\title{
Signal Transduction in Primary Human T Lymphocytes in Altered Gravity During Parabolic Flight and Clinostat Experiments
}

\author{
Svantje Tauber ${ }^{a, b}$ Swantje Hauschild ${ }^{a, b}$ Katrin Paulsen ${ }^{a} \quad$ Annett Gutewort ${ }^{a, b}$ \\ Christiane Raig ${ }^{a}$ Eva Hürlimann ${ }^{a} \quad J o s e f i n e ~ B i s k u p{ }^{a}$ Claudia Philpot ${ }^{c}$ \\ Hartwin Lier ${ }^{d}$ Frank Engelmann ${ }^{\mathrm{d}, \mathrm{e}}$ Antonella Pantaleo ${ }^{f}$ Augusto Cogolia \\ Proto Pippia $^{f} \quad$ Liliana E. Layer ${ }^{a} \quad$ Cora S. Thiel ${ }^{a, b} \quad$ Oliver Ullrich ${ }^{a, b, g, h}$ \\ anstitute of Anatomy, Faculty of Medicine, University of Zurich, Zurich, Switzerland; bepartment \\ of Machine Design, Engineering Design and Product Development, Institute of Mechanical \\ Engineering, Otto-von-Guericke-University Magdeburg, Magdeburg, Germany; ' German Aerospace \\ Center, Space Agency, Bonn, Germany; ${ }^{d K E K ~ G m b H, ~ B a d ~ S c h m i e d e b e r g, ~ G e r m a n y ; ~ e U n i v e r s i t y ~ o f ~}$ \\ Applied Science Jena, Jena, Germany; ${ }^{\mathrm{f}}$ Department of Biomedical Sciences, University of Sassari,

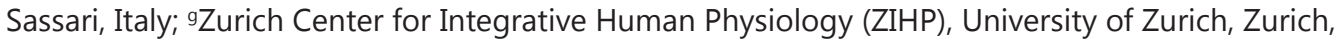 \\ Switzerland; " hStudy Group "Magdeburger Arbeitsgemeinschaft für Forschung unter Raumfahrt- und \\ Schwerelosigkeitsbedingungen" (MARS), Otto-von-Guericke-University Magdeburg, Magdeburg, \\ Germany
}

\section{Key Words}

T cell activation $\bullet$ Microgravity $\bullet$ Gravi-sensitivity $\bullet$ Hypergravity $•$ Parabolic flight $•$ Clinorotation

\begin{abstract}
Background/Aims: Several limiting factors for human health and performance in microgravity have been clearly identified arising from the immune system, and substantial research activities are required in order to provide the basic information for appropriate integrated risk management. The gravity-sensitive nature of cells of the immune system renders them an ideal biological model in search for general gravity-sensitive mechanisms and to understand how the architecture and function of human cells is related to the gravitational force and therefore adapted to life on Earth. Methods: We investigated the influence of altered gravity in parabolic flight and 2D clinostat experiments on key proteins of activation and signaling in primary $\mathrm{T}$ lymphocytes. We quantified components of the signaling cascade 1.) in nonactivated T lymphocytes to assess the "basal status" of the cascade and 2.) in the process of activation to assess the signal transduction. Results: We found a rapid decrease of CD3 and IL-2R surface expression and reduced p-LAT after 20 seconds of altered gravity in nonactivated primary $T$ lymphocytes during parabolic flight. Furthermore, we observed decreased CD3 surface expression, reduced ZAP-70 abundance and increased histone H3-acetylation
\end{abstract}

S. Tauber and S. Hauschild contributed equally.

Prof. Dr. med. Dr. rer. nat. Oliver Ullrich

KARGER 125
Institute of Anatomy, Faculty of Medicine, University of Zurich, Winterthurerstrasse 190, CH-8057 Zurich, (Switzerland)

Tel. +41 4463 55310, Fax+41 4463 55498, E-Mail oliver.ullrich@uzh.ch 
in activated T lymphocytes after 5 minutes of clinorotation and a transient downregulation of CD3 and stable downregulation of IL-2R during 60 minutes of clinorotation. Conclusion: CD3 and IL-2R are downregulated in primary $T$ lymphocytes in altered gravity. We assume that a gravity condition around $1 \mathrm{~g}$ is required for the expression of key surface receptors and appropriate regulation of signal molecules in T lymphocytes.

Copyright $\odot 2015$ S. Karger AG, Basel

\section{Introduction}

Beginning already in the early days of human spaceflight, an enhanced susceptibility to infections has been observed among astronauts [1-4], while initial evidence of disturbed cellular function appeared during investigations of lymphocytes from astronauts of the Soyuz and Skylab missions $[5,6]$. The first clear evidence of cellular sensitivity to gravity was found during the first Spacelab-Mission, where it could be demonstrated that the proliferative response of lymphocytes to mitogenic stimulation in vitro was strongly impaired under space conditions [7]. Consequently, the impairment of lymphocyte activation and the resulting immune deficiency is considered as a serious limitation for manned long-term space flights [8]. Many studies have revealed strong effects of microgravity on immune cell function [9-11], which were performed during manned space flights, on board of orbital, suborbital (sounding rockets) and parabolic flights, and were supported by ground-based facilities for simulation of microgravity such as clinorotation and 3D-random positioning machines [12]. Gravity-sensitivity in T lymphocytes was found for the cell cycle regulation [13], epigenetic regulation [14], chromatin regulation [15], expression profile of microRNA [16], cell motility [17], regulation of apoptosis [18], expression of cytokines [19], and expression of early genes of $\mathrm{T}$ lymphocyte activation, which are regulated primarily by the transcription factors NF- $\kappa B$, CREB, ELK, AP-1, and STAT $[13,20,21]$. Taken together, the phenomenon of reduced activation of $\mathrm{T}$ cells and alterations in several cellular processes during microgravity is well described. Nevertheless the exact molecular mechanisms of sensing gravitational changes are not elucidated.

The delivery of the first activation signal, the patching and capping of ConA-binding membrane proteins occurs normally in altered gravity [9]. At the same time, transcriptional regulation relevant in $\mathrm{T}$ cell activation is influenced by gravitational change (see above). Therefore the existence of gravity-sensitive cellular targets between TCR/CD3 and gene expression regulation can be assumed. In the current study we investigated the membrane proximal signaling cascade of $\mathrm{T}$ lymphocyte activation under the influence of altered gravity to assess whether these early events of $\mathrm{T}$ cell activation are responsive to altered gravity conditions. Such responsiveness could be an underlying mechanism for the transcriptional and functional reactions of T lymphocyte activation to altered gravity. We quantified selected components of the signaling cascade 1.) in non-activated T lymphocytes to assess the "basal status" of the cascade and 2.) in the process of activation to assess the signal transduction.

The quantified molecules were CD3, ZAP-70, LAT phosphorylated at tyrosine 171 (LAT (pY171)), acetyl-histone $\mathrm{H} 3$ and IL-2R, all indispensable mediators of $\mathrm{T}$ cell activation. The $\mathrm{T}$ cell antigen receptor (TCR) is a protein complex on the cell surface mediating $\mathrm{T}$ lymphocyte activation and consists of variable $\alpha$ and $\beta$ chains non-covalently linked to the non-polymorphic CD3 proteins, dimers of $\gamma \varepsilon, \delta \varepsilon$ or $\zeta \zeta$ chains. CD3 proteins transduce signals from the engaged TCR via phosphorylation of their immunoreceptor tyrosinebased activation motifs (ITAMs) located within their intracellular tails. Then, recruitment of CD3ろ-chain-associated protein kinase ZAP-70, a member of the protein-tyrosine kinase family, is followed by a cascade of phosphorylation events [22]. Among its targets are the transmembrane adapter protein linker for the activation of T cells (LAT), which contains nine tyrosines that are phosphorylated during $\mathrm{T}$ cell activation $[23,24]$. LAT binds several other signaling molecules, one of them being the C-terminal SH2 domain of phospholipase 
$\mathrm{C} \gamma 1$ (PLC $\gamma 1$ ) [25], which regulates $\mathrm{Ca}^{2+}$ and diacylglycerol (DAG)-induced responses, cytoskeletal rearrangements and integrin activation pathways. Signaling of IL-2 through IL$2 \mathrm{R}$ is required to enable lymphocytes to pass the G1 checkpoint when ConA activation of the TCR-CD3 complex and co-stimulation by anti-CD28 cause non-activated T cells to exit G0 phase and enter G1 phase of the cell cycle, a prerequisite for clonal expansion during immune response [26]. Activation of the IL-2R promotes also an activation cascade by recruitment of the adaptor Src homology 2 domain containing transforming protein 1 (SHC1), in which in turn activates the phosphoinositide 3-kinase (PI3K) and mitogen-activated protein kinase (MAPK) pathways, the latter including p44/42 MAPK (ERK1/2). T lymphocyte activation finally results in differential gene expression. This is not only mediated by transcription factor induction, but also by chromatin condensation and decondensation. Histones are highly post-translationally modified including the covalent attachment of methyl or acetyl groups to lysine and arginine amino acids and the phosphorylation of serine or threonine. Since recent findings suggest a possible role of histone acetylation in the transduction of gravitational effects $[13,14]$, we quantified acetyl-histone $\mathrm{H} 3$ in response to altered gravity.

We performed experiments on a parabolic flight during the $19^{\text {th }}$ DLR parabolic flight campaign providing $22 \mathrm{~s}$ microgravity and used ground-based simulation of microgravity using a 2D-clinostat providing 5-60 min simulated microgravity. The molecules of interest were analyzed by relative quantification using immunofluorescent staining and flow cytometry. Results were compared to experiments on board of the MASER-12 sounding rocket [27] providing 5 min of microgravity, which were conducted using the same cell type and activation- and fixation regimes and analyzed using the same method.

\section{Materials and Methods}

Isolation of $\mathrm{CD} 4^{+}$primary human T lymphocytes

For parabolic flight experiments and for clinorotation experiments CD4+ primary human T lymphocytes were used. Cells were isolated from buffy coats obtained from the blood donation center Zurich ("Blutspende Zürich", Switzerland). Donors were healthy persons of either sex and between 33 and 65 years old. They gave their written consent that their blood or certain components may be used for research purposes. $\mathrm{T}$ lymphocytes were not pooled, but taken from single donors for each experimental setup. This was done to avoid uncontrolled lymphocyte activation. First, PBMCs were isolated using Ficoll density gradient centrifugation. Therefore, buffy coats were diluted with an equal volume of PBS (Biochrom, Berlin, Germany), layered on top of Ficoll-Paque PREMIUM (GE Healthcare, Solingen, Germany) and centrifuged for 30 min at $1500 \mathrm{~g}$ without brake. The PBMC layer was collected from the interphase and washed with PBS. CD4 ${ }^{+} \mathrm{T}$ lymphocytes were isolated from PBMCs by positive magnetic bead selection using BD IMag Anti-Mouse CD4 Particles (BD Biosciences, Allschwill, Switzerland) as described in the manufacturer's protocol. Isolated human CD4+ ${ }^{+}$lymphocytes were suspended in RPMI 1640 medium (Biochrom) supplemented with 10\% FCS Superior (Biochrom), $100 \mathrm{U} / \mathrm{ml}$ penicillin and $100 \mu \mathrm{g} / \mathrm{ml}$ streptomycin (Gibco ${ }^{\circledR} /$ Life Technologies, Zug, Switzerland) and cultured at $37^{\circ} \mathrm{C}$ in $5 \% \mathrm{CO}_{2}$ atmosphere for 3-4 days before performance of experiments.

Parabolic flights as microgravity research platform

During a parabolic maneuver, an aircraft is weightless by flying on a Keplerian trajectory, described as an unpropelled body in ideally frictionless space subjected to a centrally symmetric gravitational field [28]. During this free-fall trajectory, the resultant of all forces acting on the aircraft other than gravity is nulled. During a flight campaign, which normally consists of three individual flights, 31 parabolas are flown on each flight, with 93 parabolas in total. A parabolic maneuver results in a 22 second phase of hypergravity (1.8g), followed by a 22 second phase of reduced gravity (microgravity) and a second phase of 22 seconds hypergravity (Fig. 1a). Special designated flight areas were above the Atlantic Ocean and the Mediterranean Sea. Three researchers executed the experiments on board during each flight.

Experiments were conducted on the second flight day of the $19^{\text {th }}$ Parabolic Flight Campaign of the German Aerospace Center ("Deutsches Zentrum für Luft- und Raumfahrt", DLR) in Bordeaux, France. The campaign used the unique large aircraft that is licensed in Europe to perform parabolic flights for 
Fig. 1. Technology for cell culture experiments during parabolic flights on board the Airbus A300 ZERO-G and in 2D clinorotation. A. During the Parabolic Flight maneuver, the aircraft gradually pulls up its nose and starts climbing at an angle of approximately 45 degrees. This results in an acceleration of around $1.8 \mathrm{~g}$ which lasts $22 \mathrm{~s}$. The engine thrust is then reduced to the minimum required to compensate for air-drag, and the aircraft is in a free-fall condition lasting approximately 22 seconds, during which microgravity is achieved. Acceleration in $\mathrm{x}-, \mathrm{y}-$ and $\mathrm{z}$-axis is below $2 \times 10^{-3} \mathrm{~g}$ at all times during the $0 \mathrm{~g}$ phase of the parabola. The aircraft must then pull out of the parabolic arc, a maneuver which gives rise to another 22 -second period of $1.8 \mathrm{~g}$ on the aircraft, after which it returns to normal horizontal flight. Inflight $1 \mathrm{~g}$ samples were fixed during horizontal flight prior to parabolic

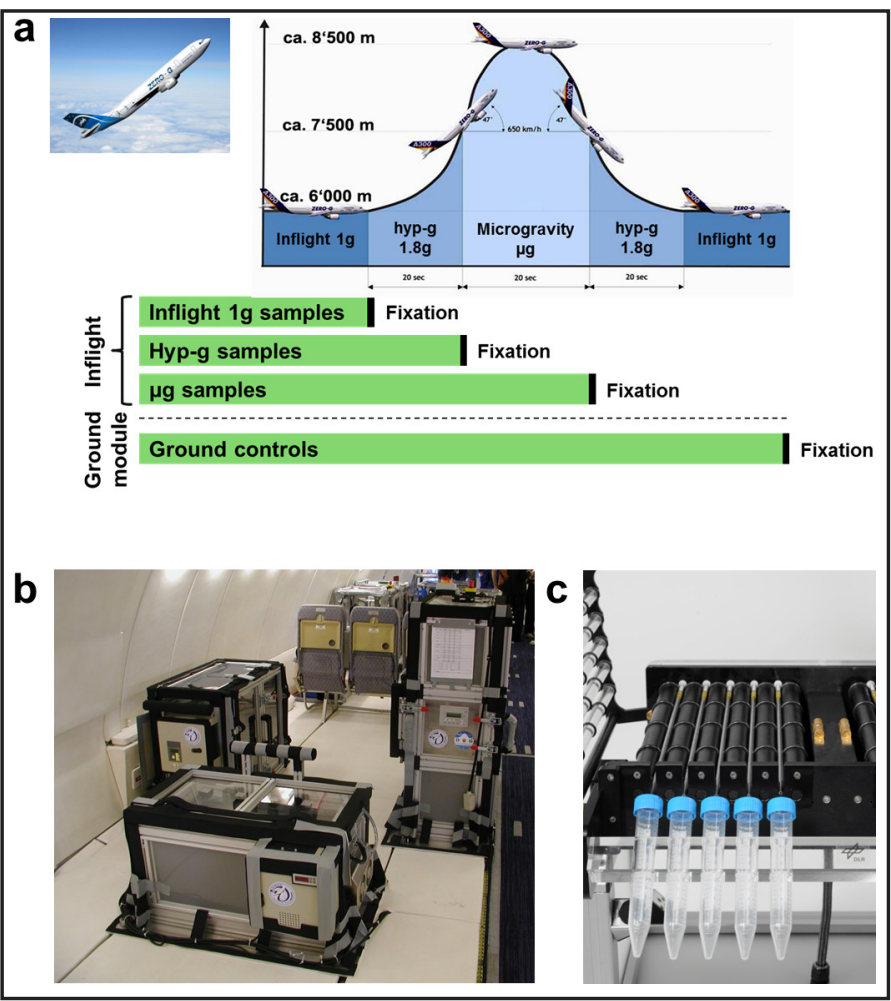
maneuvers, hyp-g samples were fixed after $20 \mathrm{sec}$ of $1.8 \mathrm{~g}$ of the first parabola, and $\mu \mathrm{g}$ samples were fixed at the end of the $\mu \mathrm{g}$ phase. Each group consisted of three samples. Fixation was achieved by addition of $50 \mathrm{ml}$ of $5 \%$ formaldehyde in PBS. Subsequently, cells were stored at $4^{\circ} \mathrm{C}$ until landing of the airplane. B. Experimental setting consisting of an incubator rack to store the cell containers temporarily before the experiment at $37^{\circ} \mathrm{C}$ (left), an experimental rack in which all active aggregates are accommodated and where the living cells are handled during altered gravity (right), and a cooling rack to temporarily store all cell containers after the injection of the stop/fixation liquid at $4^{\circ} \mathrm{C}$ until landing (front). C. A fast-rotating two-dimensional (2D) clinostat manufactured by the German Aerospace Center (DLR, Cologne, Germany) was used to provide simulated microgravity. Under the chosen experimental conditions ( $60 \mathrm{rpm}, 4 \mathrm{~mm}$ pipette diameter) a maximal residual acceleration of $4 \times 10^{-3} \mathrm{~g}$ is achieved at the outer radius of the pipette and decreases towards the center.

research purposes, the Airbus A300 ZERO-G. This aircraft is a specially configured test aircraft operated by NOVESPACE (Bordeaux, France) according to the standing orders of NOVESPACE and the CEV (Centre d'essai en vol).

\section{In-flight hardware for parabolic flight experiments}

A custom-made hardware meeting the requirement for experiments with human cell culture on board the Airbus A300 ZERO-G was developed in collaboration with KEK GmbH, Germany (Fig. 1b). The system has already been used successfully for cell culture experiments during the $8^{\text {th }}, 9^{\text {th }}, 10^{\text {th }}, 13^{\text {th }}, 14^{\text {th }}$ and $16^{\text {th }}$ DLR Parabolic Flight Campaigns and during the $45^{\text {th }}$ ESA Parabolic Flight Campaign $[13,15]$. The system consists of double-sealed cell containers holding the $\mathrm{T}$ lymphocytes and three experimental modules that supply storage of samples before the experiment, half-automated performance of the experiment and storage of the processed samples. The first module holds the cell containers at $36.5^{\circ} \mathrm{C}$ in a hanging position. From there, containers are transferred into the second module manually. In this module, cells were fixed by addition of fixation reagent upon triggering. Triggering was done manually at defined time intervals (20 seconds) after the onset of the gravitational condition of interest, resulting in the addition of fixation fluid. The third experimental module served as in-flight storage for the fixated samples at $4^{\circ} \mathrm{C}$. Three samples could be processed in parallel. Sample exchange required approximately one minute, requiring a defined procedure by three trained persons. Two persons loaded and unloaded the cell containers in the working rack within 
60 seconds of the $1 \mathrm{~g}$ phase between each parabola. A third person was in charge of operating the control unit and monitoring the subsystems. Each was trained to overtake any other position in a case of emergency.

\section{Experimental setup, sample logistics and protocol of parabolic flight experiments}

Samples were prepared and analyzed in our laboratory at the University of Zurich, Switzerland. T lymphocytes from a single donor were used. Four days before the flight, cells were isolated and cultivated at a concentration of $1 \times 10^{6}$ cells $/ \mathrm{ml}$. 32-28 hours before the flight, cells were supplied with fresh medium and filled into the cell containers of the hardware under sterile conditions. The samples consisted of $10 \mathrm{ml}$ cell suspension with a concentration of $1 \times 10^{6}$ cells/ml in RPMI 1640, 10\% FCS, 1\% Glutamine, 0.1\% Ciprobay, $1 \%$ Amphotericin B. Samples were transported by train to the NOVESPACE Facilities at Bordeaux Mérignac airport at $20-25^{\circ} \mathrm{C}$ in temperature-isolated boxes. After arrival (15hours before the parabolic flight) cells were incubated at $37^{\circ} \mathrm{C}$ until they were integrated into the flight hardware $30 \mathrm{~min}$ before flight. About one hour after takeoff, the first parabolic maneuver was initiated. Experimental groups on board comprised $1 \mathrm{~g}$ samples, hypergravity (hyp-g) samples and microgravity ( $\mu \mathrm{g})$ samples, complemented by ground controls. $1 \mathrm{~g}$ samples were fixed during horizontal flight prior to parabolic maneuvers, hyp-g samples were fixed at the end of a 20 second $1.8 \mathrm{~g}$ phase of the first parabola, and $\mu \mathrm{g}$ samples were fixed at the end of the microgravity phase of the same parabola, respectively. Each group consisted of three samples. Fixation was achieved by addition of $50 \mathrm{ml}$ of 5\% formaldehyde in PBS resulting in a final concentration of $4.2 \%$ formaldehyde. For the formaldehyde concentration, the upper tested margin for sample processing and analysis was chosen in order to ensure rapid and efficient fixation even in the case of an unexpected pump function disturbance. Subsequently, cells were stored at $4{ }^{\circ} \mathrm{C}$ until landing of the airplane. Ground controls were fixed after the flight in the hardware on-board. Cells of all samples were then centrifuged at $300 \mathrm{~g}$ for $5 \mathrm{~min}$ and resuspended in $2 \mathrm{ml}$ Stain Buffer BSA (BD Biosciences). Samples were transported by train back to Zurich where they were stained and analyzed within four weeks after flight. Storage and transport of the flight samples was at $4^{\circ} \mathrm{C}$.

\section{$2 D$ clinorotation as source of simulated microgravity}

A fast-rotating two-dimensional (2D) clinostat was used to provide simulated microgravity (Fig. 1c). The principle of clinorotation-induced microgravity is rotation of cells in a pipette perpendicular to the Earth's gravity. During clinorotation the speed of rotation has to be adjusted fast enough to avoid sedimentation, and at the same time slow enough to avoid centrifugation. The cells are then moving on a circular path and should no longer perceive the rapidly turning gravity vector (experience "weightlessness") because the accelerating forces compensate each other [29]. The clinostat that was used for our experiments was manufactured and certified for cell culture experiments by the German Aerospace Center (DLR, Cologne, Germany). Under our chosen experimental conditions ( $60 \mathrm{rpm}, 4 \mathrm{~mm}$ pipette diameter), a maximal residual acceleration of $2 \times 10^{-3} \mathrm{~g}$ was calculated at the outer radius of the pipette and decreases towards the center. 2D clinorotation with this experimental setup is an established model system for the simulation of microgravity using $\mathrm{T}$ lymphocytes and other cell types [13, 30-32] A recent study (ESA Ground-based facilities / GBF project) compared different ground based microgravity platforms to real microgravity and identified fast 2D clinorotation as a good simulation of microgravity suitable for cell culture studies. In accordance to recommendations from the same study we will refer to clinorotation-induced microgravity as simulated microgravity [33].

\section{Experimental setup and protocol of clinorotation}

T lymphocytes from a single donor were used, from one donor for $5 \mathrm{~min}$ experiments and from a second donor for the 5-60 min experiments. Experimental groups of the clinorotation studies comprised simulated microgravity ( $\mathrm{s}-\mu \mathrm{g}$ ) samples, $1 \mathrm{~g}$ samples and baseline samples. In some experiments, cell culture samples were included as additional controls. Each group consisted of 3-4 independent samples. Human CD4 $4^{+} \mathrm{T}$ lymphocytes $\left(5 \times 10^{6}\right.$ cells $\left./ \mathrm{ml}\right)$ were filled into $1 \mathrm{ml}$ serological pipettes (BD Biosciences). The s- $\mu \mathrm{g}$ samples were clinorotated for 5, 15, 30 or 60 minutes. Pipettes with $1 \mathrm{~g}$ samples were loaded simultaneously and placed inside the clinostat without rotation. To investigate the influence of pipette filling, baseline samples were prepared by fixing cells immediately after transferring them into the pipettes. Culture controls were taken directly from a cell culture vessel and fixed immediately. For T cell activation, Concanavalin A (ConA, Sigma-Aldrich) and anti-CD28 antibody (BD Biosciences) were added to the cells at final concentrations of 
$10 \mu \mathrm{g} / \mathrm{ml}$ (ConA) and $4 \mu \mathrm{g} / \mathrm{ml}$ (anti-CD28 antibody) directly before filling of the pipettes. The time interval needed to activate cells prior to the start of altered gravity (mixing and installing on the clinostat) was kept as short as possible and constant over all samples. All experiments were performed in a temperaturecontrolled incubator at $37^{\circ} \mathrm{C}$. After the respective time period (or directly in case of baseline samples and

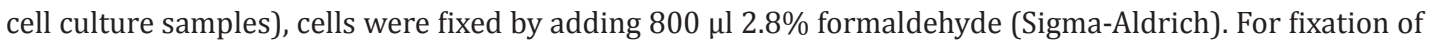
the $s-\mu \mathrm{g}$ samples the tilting mechanism of the clinostat was used, meaning that the samples were poured into the $800 \mu \mathrm{l}$ fixation solution while the pipettes were still rotating. Final concentration of formaldehyde was $1.2 \%$.and samples were fixed for 2 hours at room temperature before they were centrifuged for $5 \mathrm{~min}$ at $300 \mathrm{~g}$, resuspended in $250 \mu \mathrm{l}$ Stain Buffer BSA (BD Biosciences) and stored at $4^{\circ} \mathrm{C}$ until immunocytochemical staining.

\section{Immunocytochemical Staining and Flow cytometry analysis}

For immunocytochemical staining, samples were divided in aliquots and each aliquot was stained with one antibody. In the case of samples from parabolic flight (whole sample $2 \mathrm{ml}, 10 \times 10^{6} \mathrm{cells}$ ) aliquots of $80 \mu \mathrm{l}$, $4 \times 10^{4}$ cells were made, and in the case of samples from clinorotation (whole sample $250 \mu \mathrm{l}, 5 \times 10^{6}$ ) aliquots of $10 \mu \mathrm{l}, 20 \times 10^{4}$ cells were made. For surface staining of CD3 and IL-2R, the subsequent permeabilization step was omitted. For detection of all other proteins, cells were permeabilized with Perm Buffer III (BD Biosciences) according to the manufacturer's instructions. Then, cells were centrifuged at $300 \mathrm{~g}$ for $5 \mathrm{~min}$, supernatant was removed and cells were resuspended in $80 \mu \mathrm{l}$ of Stain Buffer BSA containing the respective Alexa Fluor ${ }^{\circledR}$ 488-conjugated antibody. The following antibodies and respective dilutions were used: antiCD3 (PromoCell, Heidelberg, Germany, custom labeled PK-AB913-144), 1:80; anti-IL-2R (PromoCell, custom labeled PK-AB913-104), 1:40; anti-Phospho-p44/42 MAPK (Erk1/2) (Thr202/Tyr204) (Cell Signaling, Boston USA, 4374), 1:160; anti-Zap-70 (D1C10E) (Cell Signaling, 9473), 1:80; anti-acetyl-histone H3 (Lys9) (Cell Signaling, 9683), 1:400; anti-LAT (pY171) (BD Bioscience, 558519), 1:8; Mouse (MOPC-21) mAb IgG1 Isotype Control (Cell Signaling, 4878), 1:80; Rabbit (DA1E) mAb IgG Isotype Control (Cell Signaling, 2975), 1:40. After $30 \mathrm{~min}$ of incubation in antibody solution, $250 \mu \mathrm{l}$ Stain Buffer BSA were added to each reaction. Flow cytometry data were collected on a FACSCanto II flow cytometer (BD Biosciences) using FACSDiva software and analyzed using FlowJo software (Tree Star, Ashland, OR, USA). A gate was set around the T cell population using forward- and sideward-scatter which excluded cell debris and cell doublets. The same gate was used for all analyzed samples. Results are expressed as the relative fluorescent intensity (RFI) which was calculated by dividing the geometric mean of fluorescent intensity (MFI) of the sample incubated with the antibody specific for the antigen of interest by the MFI of the same sample incubated with the isotypeand species-matched unspecific control antibody.

\section{Statistical Analysis}

Statistical analysis was performed using the Student's t-test by PRISM software (GraphPad software Inc., San Diego, CA). A p-value of $<0.05$ was considered statistically significant. RFI values were given with one decimal, whereas statistical tests were performed with the original three decimal values. Values are expressed as dot plots with the mean according to recommendations of Cumming et al. [34].

\section{Results}

Rapid decrease of CD3 and IL-2R surface expression and reduced p-LAT in T lymphocytes upon 20 seconds of altered gravity during parabolic flight

Human $\mathrm{CD}^{+} \mathrm{T}$ lymphocytes were exposed to inflight $1 \mathrm{~g}$, hypergravity and microgravity during parabolic flight. Additionally ground control samples (flight-identical hardware but no flight) were taken to observe possible effects of the flight maneuvers before parabolas. Components of $\mathrm{T}$ cell signaling were quantified by flow cytometry. Results are shown in Fig. 2. An overview of significant up- and downregulations of the investigated molecules is given in Table 1. Comparison of the inflight $1 \mathrm{~g}$ samples with the ground controls showed no significant difference in abundance of all 6 investigated markers (CD3, ZAP-70, LAT (pY171), P-p44/42 MAPK, acetyl-histone H3, IL-2R) indicating that the flight phase of the aircraft before onset of the parabolic flight maneuvers had no effect. Surface staining of CD3 was 
Fig. 2. Analysis of selected molecules involved in $\mathrm{T}$ lymphocyte signal transduction in non-activated $\mathrm{T}$ lymphocytes during parabolic flight. $\mathrm{CD}^{+} \mathrm{T}$ lymphocytes were exposed to the first parabola of a parabolic flight. Samples were fixed and analyzed before the first parabola (inflight 1g), after the first 20 seconds of hypergravity phase (hyp-g) or after the first 20 seconds of microgravity phase $(\mu \mathrm{g})$. Ground controls (GC) were performed in the same experimental hardware after landing. Samples were immunofluorescently stained and analyzed by flow cytometry; data are expressed as relative fluorescence intensity (RFI). Single data points and means are shown for each experimental group $(* \mathrm{p}<0.05, * * \mathrm{p}<0.01)$

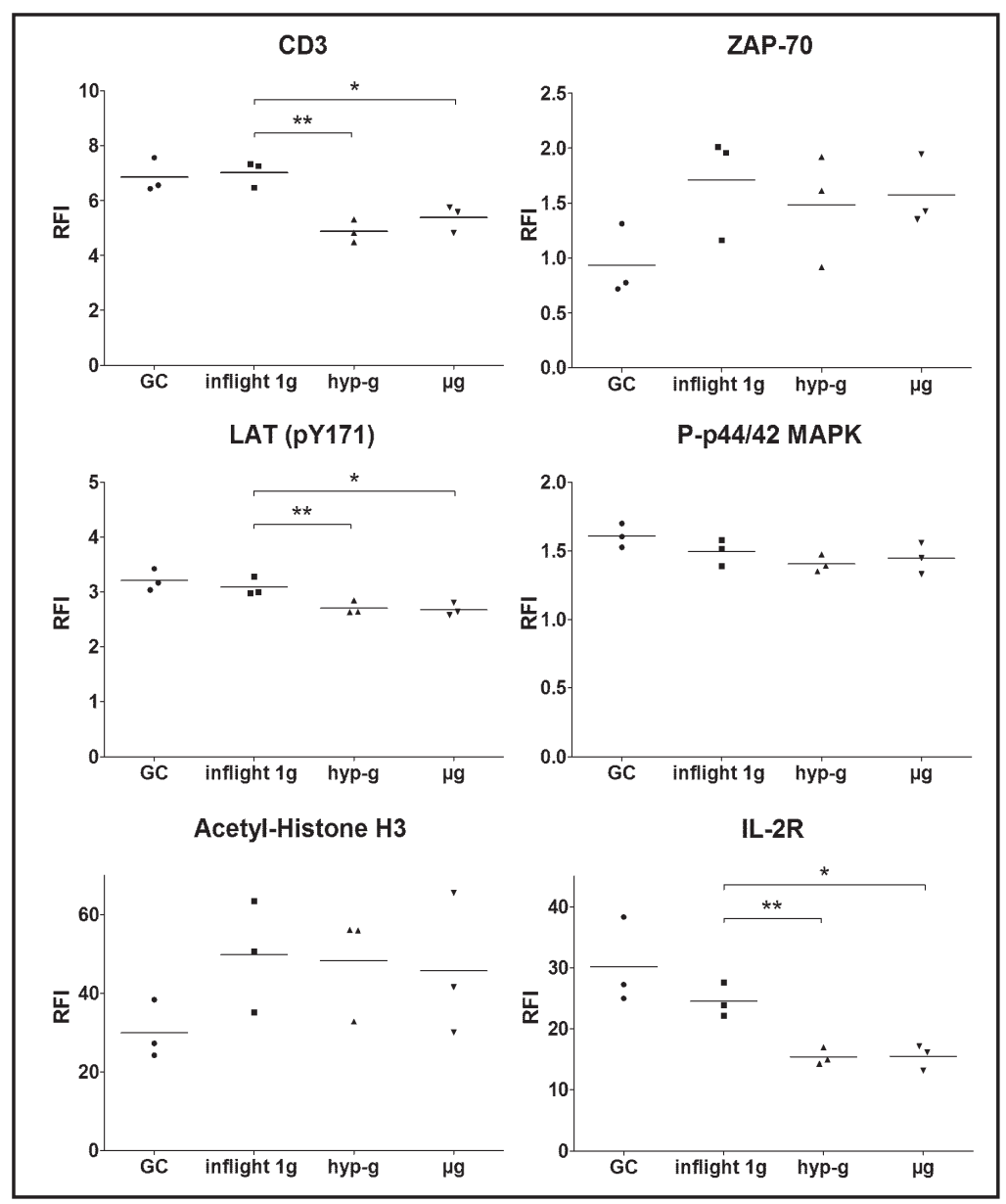

significantly reduced in hyp-g samples $(4.9+/-0.2, \mathrm{n}=3)$ and in $\mu$ g samples $(5.4+/-0.3, \mathrm{n}=3)$ compared to inflight $1 \mathrm{~g}$ samples ( $\mathrm{p}=0.004$ and $\mathrm{p}=0.015$, respectively). Hyp-g and $\mu \mathrm{g}$ samples did not differ significantly from each other $(p=0.245)$.

The level of LAT phosphorylated at tyrosine 171 (LAT (pY171)) in the hyp-g samples $(2.7+/-0.1, \mathrm{n}=3)$ and in the $\mu \mathrm{g}$ samples $(2.8+/-0.1, \mathrm{n}=3)$, LAT (pY171) was significantly downregulated compared to the inflight $1 \mathrm{~g}$ samples ( $\mathrm{p}=0.0346$ and $\mathrm{p}=0.0266$, respectively). Hyp-g samples and $\mu$ g samples did not differ from each other ( $\mathrm{p}=0.767)$.

The level of ZAP-70 staining in the T lymphocytes was not significantly different among all four experimental groups. No difference was detected in the level of phosphorylated $\mathrm{p} 44 / 42$ MAPK in response to the different gravitational conditions. Also the level of acetylated histone $\mathrm{H} 3$ did not change among the experimental groups.

The level of IL-2R in the hyp-g samples $(15.4+/-0.8, n=3)$ and in the $\mu g$ samples $(15.5+/-$ $1.2, n=3)$ were significantly decreased compared to the inflight $1 \mathrm{~g}$ samples $(\mathrm{p}=0.007$ and $\mathrm{p}=0.010$, respectively).

Enhanced histone H3 acetylation in T lymphocytes after 5 minutes of clinorotation

Having seen effects of short-term altered gravity on the key proteins of T lymphocyte signaling induced by 20 seconds hyp-g and $\mu \mathrm{g}$ phases of the parabolic flight, we then investigated the influence of 5 minutes of simulated microgravity in 2D clinorotation experiments. In the first set of clinorotation experiments, the effects of microgravity on non-activated cells was investigated. Results are expressed as RFI and shown in Fig. 3. An overview of significant up- and downregulations of the investigated molecules is given in Table 1. 
Table 1. Summary of the qualitative changes of selected proteins of $\mathrm{T}$ lymphocyte signal transduction in non-activated or activated cells induced by altered gravitational conditions during parabolic flight, suborbital flight and 2D clinorotation. Cells were either not stimulated or stimulated with Concanavalin A (ConA)/ CD28 and exposed to parabolic flight, suborbital flight or clinorotation. GC, ground control (cells that have been exposed to the flight hardware of parabolic flight or suborbital flight experiments); BL, baseline samples (cells have been shortly in the experimental hardware of clinorotation experiments before fixation) CC, cell culture control (optimal culture conditions before fixation); $1 \mathrm{~g}$, normal gravitational conditions (cell were clinostat but not rotated); inflight $1 \mathrm{~g}$ (cells were fixed before parabolas during parabolic flight or were on an onboard centrifuge providing $1 \mathrm{~g}$ during suborbital flight); hyp-g, hypergravity (fixation after the $1.8 \mathrm{~g}$ phase during parabolic flight or after the launch phase of suborbital flight); $\mu$, microgravity during parabolic flight or suborbital flight; s- $\mu$ g, simulated microgravity provided by clinorotation. Cells were stained by immunocytochemistry, staining was quantified by flow cytometry analysis and the relative fluorescent intensity was calculated. $\downarrow$ indicates a downregulation, $\uparrow$ indicates an upregulation, - indicates no significant difference within the compared groups; nd, not determined; * $\mathrm{p}<0.05,{ }^{* *} \mathrm{p}<0.01$

\begin{tabular}{cccccccc}
\hline \multicolumn{4}{c}{ Signal molecule } \\
CD3 & ZAP- & LAT & P-p44/42 & Acetyl- & IL- \\
(pY171) & MAPK & Histone H3 & 2R \\
\hline
\end{tabular}

19th DLR parabolic flight campaign / non-activated T lymphocytes

Flight controls (flight compared to ground, inflight $1 \mathrm{~g}$

vs. GC)

Hypergravity compared to normal gravity

(hyp-g vs. inflight 1g)

Microgravity compared to normal gravity

( $\mu$ g vs. inflight $1 \mathrm{~g}$ )

Microgravity compared to hypergravity

( $\mu \mathrm{g}$ vs. hyp-g)

2D clinorotation (5 min) / non-activated T lymphocytes

Hardware control

(BL vs. CC)

5 min hardware control

( $s-\mu \mathrm{g}$ and $1 \mathrm{~g}$ vs. BL)

5 min clinorotation

(s- $\mu$ g vs. 1g)

Hardware control

(s- $\mu$ g and $1 \mathrm{~g}$ vs. CC)

5 min clinorotation

(s- $\mu \mathrm{g}$ vs. $1 \mathrm{~g}$ )

15 min clinorotation

(s- $\mu \mathrm{g}$ vs. $1 \mathrm{~g}$ )

30 min clinorotation

(s- $\mu \mathrm{g}$ vs. $1 \mathrm{~g}$ )

60 min clinorotation

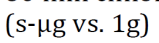

2D clinorotation (5-60 min), ConA/CD28-activated T lymphocytes

$\begin{array}{cccccc}\downarrow^{*} & - & \uparrow * & \uparrow * * & - & - \\ \downarrow^{* *} & \downarrow^{*} & - & - & \uparrow * & - \\ \downarrow^{*} & \text { nd } & \text { nd } & \text { nd } & \text { nd } & - \\ - & \text { nd } & \text { nd } & \text { nd } & \text { nd } & \downarrow^{*} \\ - & \text { nd } & \text { nd } & \text { nd } & \text { nd } & \downarrow^{*}\end{array}$

Hardware control compared to cell culture

(GC vs. CC)

Launch phase / hypergravity compared to normal

gravity on ground (hyp-g vs. GC)

(hyp-g vs. 1g)

MASER-12 suborbital space flight / non-activated T lymphocytes (6 min)

Microgravity compared to normogravity

( $\mu$ g vs. inflight $1 \mathrm{~g}$ )

MASER-12 suborbital space flight / ConA/CD28-activated T lymphocytes (6 min)

Microgravity compared to normogravity

( $\mu$ g vs. inflight $1 \mathrm{~g})$

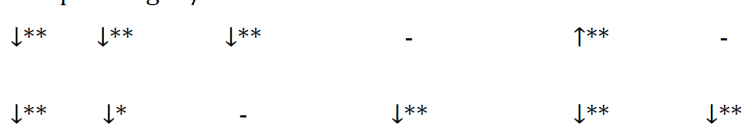

There was no difference between cell culture controls and baseline samples in any of the investigated markers, indicating that the filling of the clinostat pipettes had no effect 


\section{Cellular Physiology and Biochemistry}

Cell Physiol Biochem 2015;35:1034-1051

\begin{tabular}{l|l}
\hline DOI: $10.1159 / 000373930$ & (C) 2015 S. Karger AG, Basel
\end{tabular}

www.karger.com/cpb

Tauber et al.: T Cell Signaling in Short Term Altered Gravity
Fig. 3. Analysis of selected molecules involved in $\mathrm{T}$ lymphocyte signal transduction in non-activated $\mathrm{T}$ lymphocytes during $2 \mathrm{D}$ clinorotation $(s-\mu g)$ or $1 \mathrm{~g}$ for 5 min. $\mathrm{CD}^{+} \mathrm{T}$ lymphocytes were exposed to simulated microgravity or to $1 \mathrm{~g}$ for $5 \mathrm{~min}$ using a 2Dclinostat. Experimental groups comprise control cells from standard cell culture (CC), baseline samples that were exposed to the experimental hardware (BL), cells that were clinorotated ( $s-\mu \mathrm{g})$ and cells that were placed on a nonrotating part inside the clinostat in parallel to the $s-\mu$ g samples (1g). Samples were immunofluorescently stained and analyzed by flow cytometry; data are expressed as relative fluorescence intensity (RFI). Single data points and means are shown for each experimental group $(* \mathrm{p}<0.05$, ** $\mathrm{p}<0.01$ ).

Fig. 4. Analysis of selected molecules involved in $\mathrm{T}$ lymphocyte signal transduction in ConA/ CD28-activated $\mathrm{T}$ lymphocytes during clinorotation $(s-\mu g)$ or $1 \mathrm{~g}$ for $5 \mathrm{~min}$. Concanavalin A (ConA)/CD28-activated $\mathrm{CD}^{+}{ }^{+} \mathrm{T}$ lymphocytes were exposed to simulated microgravity for $5 \mathrm{~min}$ using a 2D-clinostat. Experimental groups comprised baseline samples that were exposed to the experimental hardware (BL), cells that were clinorotated (s$\mu \mathrm{g}$ ), and cells that were placed on a non-rotating part inside the clinostat in parallel to the $s-\mu \mathrm{g}$ samples (1g). Samples were immunofluorescently stained and analyzed by flow cytometry; data are expressed as relative fluorescence intensity (RFI). Single data points and means are shown for each experimental group $(* \mathrm{p}<0.05, * * \mathrm{p}<0.01)$.
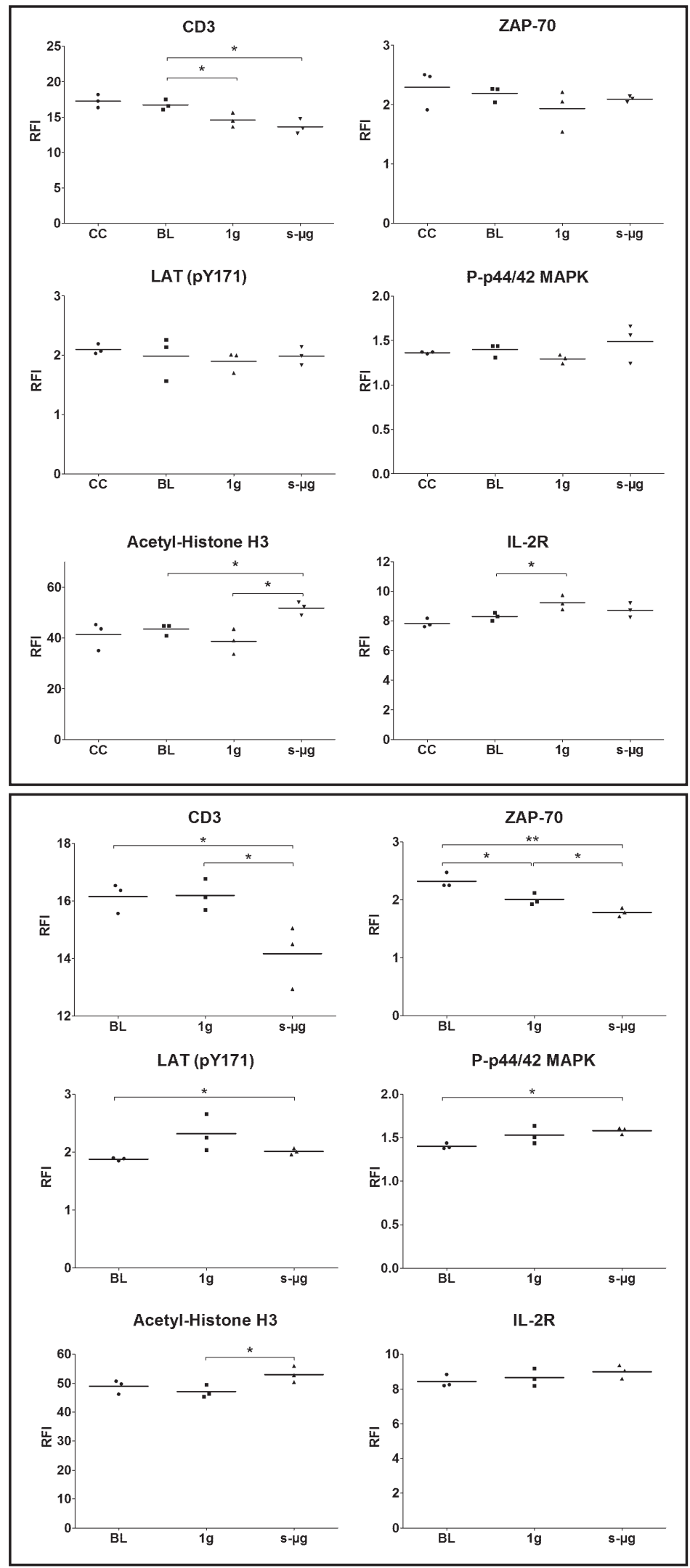

on the abundance of the molecules. Therefore in the following, $s-\mu g$ and $1 \mathrm{~g}$ samples will be compared only to the baseline samples and not additionally to the CC controls. 
Fig. 5. CD3 and IL-2R surface expression of activated $\mathrm{T}$ lymphocytes in simulated microgravity during clinorotation. Concanavalin A (ConA)/CD28-activated $\mathrm{CD}^{+}{ }^{+} \mathrm{T}$ lymphocytes were exposed to simulated microgravity $(s-\mu \mathrm{g})$ for $5 \mathrm{~min}, 15 \mathrm{~min}, 30 \mathrm{~min}$ or $60 \mathrm{~min}$ using a 2D-clinostat. $1 \mathrm{~g}$ control cells (1g) were placed on a non-rotating part inside the clinostat in parallel to the $s-\mu g$ samples. Baseline samples (BL) were taken directly after activation and insertion of cells into the hardware. Samples were immunofluorescently stained for surface CD3 or IL-2R and analyzed by flow cytometry; data are expressed as relative fluorescence intensity (RFI). Single data points and means are shown for each experimental group $(* \mathrm{p}<0.05$, $* * \mathrm{p}<0.01)$.

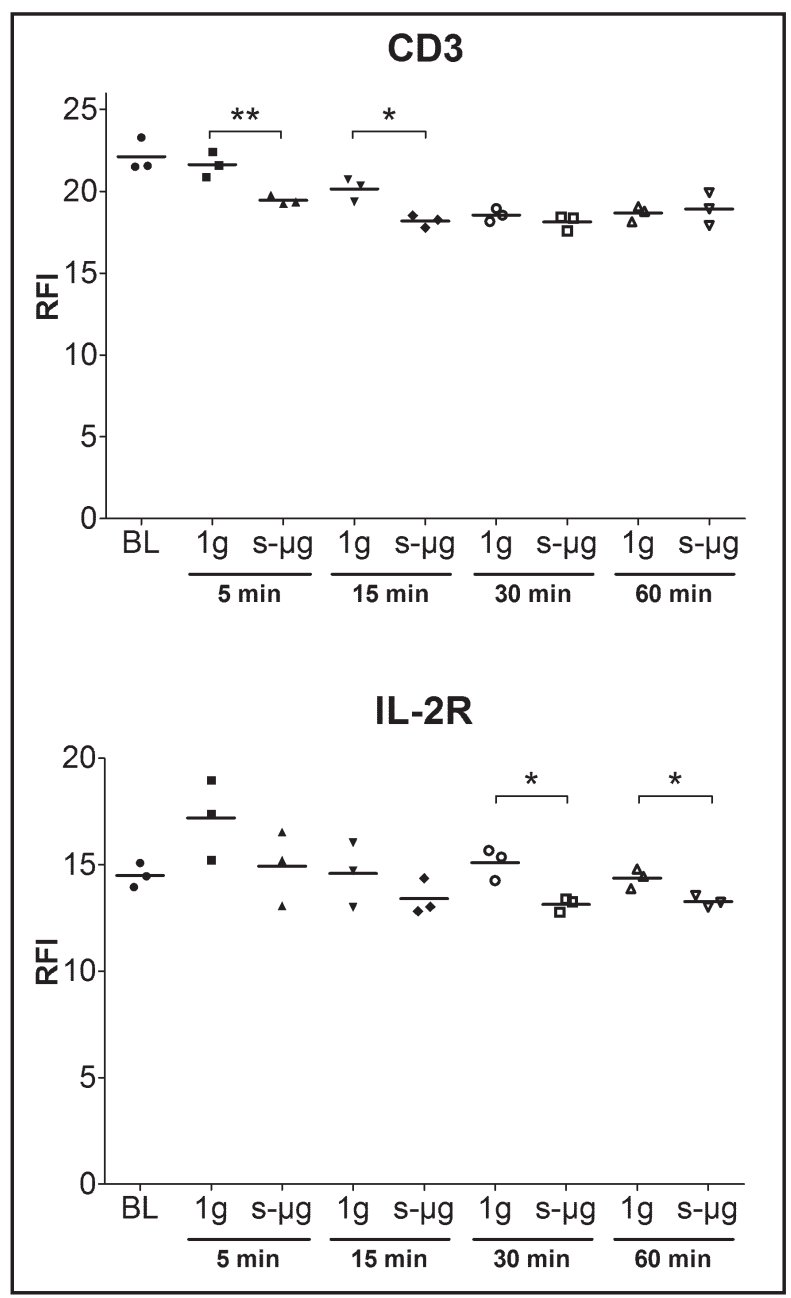

Surface staining of CD3 in $1 \mathrm{~g}$ samples $(14.6+/-0.6, \mathrm{n}=3)$ and $\mathrm{s}-\mu \mathrm{g}$ samples $(13.6+/-0.6$, $\mathrm{n}=3$ ) did not differ from each other significantly $(\mathrm{p}=0.313)$ giving no evidence for sensitivity to gravity. However, CD3 staining was decreased in $1 \mathrm{~g}$ samples and in $\mathrm{s}-\mu \mathrm{g}$ samples compared to baseline samples $(16.7+/-0.4, \mathrm{n}=3 ; \mathrm{p}=0.040$ and $\mathrm{p}=0.014$, respectively) showing an influence of culturing the cells in the clinostat for $5 \mathrm{~min}$.

The intensities of ZAP-70 staining, and staining of LAT phosphorylated at tyrosine 171 and phosphorylated p44/42 MAPK did not differ between any of the experimental groups baseline samples.

The level of stained acetyl-histone H3 was significantly higher in $\mathrm{s}-\mu \mathrm{g}$ samples $(51.7+/$ $1.5, \mathrm{n}=3)$ compared to $1 \mathrm{~g}$ samples $(38.7+/-2.8, \mathrm{n}=3 ; \mathrm{p}=0.016)$. $1 \mathrm{~g}$ samples did not differ from baseline samples $(43.5+/-1.3, n=3 ; p=0.197)$, whereas in $s-\mu g$ samples the level was significantly higher than in baseline samples $(p=0.015)$ indicating an $s-\mu g$-induced upregulation of acetylated histone $\mathrm{H} 3$.

The only significant change of surface IL-2R expression among the experimental groups was measured between the baseline samples $(8.3+/-0.2, \mathrm{n}=3)$ and the $1 \mathrm{~g}$ samples $(9.2+/-0.3$, $\mathrm{n}=3)$, the latter having a significantly higher level $(\mathrm{p}=0.045)$. In contrast, in the $\mathrm{s}-\mu \mathrm{g}$ samples $(8.7+/-0.3, n=3)$ the level of IL-2R surface staining was neither different from the baseline samples, nor from the $1 \mathrm{~g}$ samples ( $\mathrm{p}=0.251$ and $\mathrm{p}=0.267$, respectively).

Taken together, among the investigated molecules, only for acetylated histone $\mathrm{H} 3 \mathrm{a}$ microgravity-induced change (an upregulation) was detected after 5 min of clinorotation. 
Decreased CD3 surface expression, reduced ZAP-70 abundance and increased histone H3-acetylation in Concanavalin A/CD28-stimulated T lymphocytes after 5 minutes of clinorotation

In a second set of clinorotation experiments, cells were activated by Concanavalin $\mathrm{A}$ (ConA) and CD28 to evaluate if and how microgravity changes the composition of the key components of $\mathrm{T}$ lymphocyte signaling during activation. Except for the ConA/CD28 activation, experiments were performed analogous to the previous ones. Results are depicted in Fig. 4. An overview of significant up- and downregulations of the investigated molecules is given in Table 1.

Activated $\mathrm{T}$ lymphocytes exposed to simulated microgravity showed a significant reduction of CD3 surface staining $(14.2+/-0.6, n=3)$ in comparison to the $1 \mathrm{~g}$ samples $(16.2+/$ $0.3, \mathrm{n}=3)$ and to the baseline samples $(16.2+/-0.3 ; \mathrm{p}=0.045$ and $\mathrm{p}=0.047$, respectively) demonstrating a sensitivity to gravity. CD3 surface staining of the $1 \mathrm{~g}$ samples was not significantly different compared to baseline samples $(\mathrm{p}=0.920)$.

ZAP-70 staining of $s-\mu \mathrm{g}$ samples $(1.8+/-0.0, \mathrm{n}=3)$ was significantly reduced in comparison to that of the $1 \mathrm{~g}$ samples $(2.0+/-0.1, \mathrm{n}=3)$ and of the baseline samples $(2.3+/-0.1, \mathrm{n}=3$; $\mathrm{p}=0.037$ and $\mathrm{p}=0.003$, respectively). Furthermore, the ZAP-70 staining of $1 \mathrm{~g}$ samples was significantly reduced compared to baseline samples $(\mathrm{p}=0.028)$. These results demonstrated a sensitivity of ZAP-70 to cultivation in the clinostat and to simulated microgravity.

Staining for LAT phosphorylated at tyrosine 171 (pY171) was found to be significantly stronger in $s-\mu$ g samples $(2.0+/-0.0, n=3)$ than in baseline samples $(1.9+/-0.0 ; p=0.019)$. The LAT (pY171) staining of $1 \mathrm{~g}$ samples $(2.3+/-0.2, \mathrm{n}=3)$ seems to be more intense than that of the baseline samples and that of $\mu \mathrm{g}$ samples, however, these differences are not significant ( $p=0.075$ and $p=0.176$, respectively), probably due to the rather big standard deviation of the $1 \mathrm{~g}$ samples.

The staining for phosphorylated p44/42 MAPK in $s-\mu g$ samples $(1.6+/-0.0, n=3)$ is significantly higher than that of baseline samples $(1.4+/-0.0, n=3 ; p=0.003)$, but not different from that of $1 \mathrm{~g}$ samples $(1.5+/-0.1, \mathrm{n}=3$; $\mathrm{p}=0.442)$. Phosphorylated $\mathrm{p} 44 / 42$ MAPK staining of baseline samples and $1 \mathrm{~g}$ samples did not differ $(\mathrm{p}=0.108)$.

Staining of acetylated histone $\mathrm{H} 3$ revealed that the level of acetyl-histone $\mathrm{H} 3$ is significantly higher in $\mathrm{s}-\mu \mathrm{g}$ samples $(53.1+/-1.6, \mathrm{n}=3)$ than in $1 \mathrm{~g}$ samples $(47.1+/-1.3, \mathrm{n}=3$; $\mathrm{p}=0.044$ ). No difference could be observed between $\mathrm{s}-\mu \mathrm{g}$ samples and baseline samples (48.9+/-1.4, $n=3 ; p=0.121$ ) or between $1 \mathrm{~g}$ samples and baseline samples $(\mathrm{p}=0.384)$.

Staining of surface IL-2R revealed no differences in the surface abundance between any of the experimental groups.

Microgravity-induced transient downregulation of CD3 and stable downregulation of IL$2 R$ during 60 minutes of clinorotation

To evaluate the development of simulated microgravity-induced effects on Tymphocyte activation over time, kinetic clinorotation experiments were performed with measurements after 5, 15, 30, and $60 \mathrm{~min}$. CD3 and IL-2R were chosen as markers for analysis, as both of these surface receptors were altered in their surface abundance upon altered gravity during the parabolic flight and clinorotation experiments. This choice covers one very early component of the $\mathrm{T}$ lymphocyte activation cascade (CD3) and one component far more downstream (IL-2R), enabling to assess possible differences in the effects of altered gravity on early and late components of T lymphocyte activation cascade. Results are shown in Fig. 5 . An overview of significant up- and downregulations of the investigated molecules is given in Table 1.

As already seen in the previous experiment, activated $\mathrm{T}$ lymphocytes exposed to clinorotation for 5 minutes ( $\mathrm{s}-\mu \mathrm{g}$ samples) were stained significantly less for CD3 (19.5+/-0.2, $\mathrm{n}=3$ ) than $1 \mathrm{~g}$ samples $(21.6+/-0.5, \mathrm{n}=3 ; \mathrm{p}=0.010)$. Likewise, after 15 minutes of clinorotation the $s-\mu$ g samples were still stained less $(18.2+/-0.2, n=3)$ than $1 \mathrm{~g}$ samples $(20.1+/-0.4$, $\mathrm{n}=3 ; \mathrm{p}=0.014)$. In contrast, after 30 and 60 minutes, no significant difference was detected anymore between $s-\mu \mathrm{g}$ samples and $1 \mathrm{~g}$ samples (30 minutes: $s-\mu \mathrm{g}$ samples $18.2+/-0.2, \mathrm{n}=3$, 
$1 \mathrm{~g}$ samples $18.6+/-0.2, \mathrm{n}=3 ; \mathrm{p}=0.293 ; 60$ minutes: $\mathrm{s}-\mu \mathrm{g}$ samples $18.9+/-0.6, \mathrm{n}=3,1 \mathrm{~g}$ samples $18.7+/-0.3, n=3 ; p=0.707$ ), suggesting an adaptation of CD3 expression to the microgravity environment.

The IL-2R staining was less intensive in $\mathrm{s}-\mu \mathrm{g}$ samples than in $1 \mathrm{~g}$ samples throughout all investigated time intervals of clinorotation. However, this difference was significant only after 30 and 60 minutes (30 minutes: $s-\mu g$ samples $13.1+/-0.2, n=3,1 \mathrm{~g}$ samples $15.1+/-0.4, \mathrm{n}=3$; $\mathrm{p}=0.014 ; 60$ minutes: $\mu$ g samples $13.3+/-0.2, \mathrm{n}=3,1 \mathrm{~g}$ samples $14.4+/-0.3, \mathrm{n}=3 ; \mathrm{p}=0.023$ ). In contrast, after 5 and 10 minutes, the difference was not significant ( 5 minutes: $s-\mu g$ samples $14.9+/-1.0, n=3,1 \mathrm{~g}$ samples $17.2+/-1.1, \mathrm{n}=3 ; \mathrm{p}=0.204 ; 15$ minutes: $\mathrm{s}-\mu \mathrm{g}$ samples $13.4+/-0.5$, $\mathrm{n}=3$, 1 g samples $14.6+/-0.9, \mathrm{n}=3 ; \mathrm{p}=0.305$ ), coherent with the previous experiment of $5 \mathrm{~min}$ clinorotation, which also revealed no significant difference between $1 \mathrm{~g}$ and $\mathrm{s}-\mu \mathrm{g}$ samples (Fig. 4). Taken together these results suggest that surface IL-2R expression is down regulated upon simulated microgravity either within $30 \mathrm{~min}$ and lasts at least for $60 \mathrm{~min}$, or (assuming that the differences between $1 \mathrm{~g}$ and $\mathrm{s}$ - $\mu \mathrm{g}$ samples would be significant with a larger sample number) is present already after $5 \mathrm{~min}$ and gets more pronounced over $60 \mathrm{~min}$.

\section{Discussion}

To investigate the influence of microgravity on signal transduction in CD4+ T lymphocytes, selected molecules that are involved in signal transduction were analyzed 1.) after $20 \mathrm{sec}$ real microgravity provided during the $19^{\text {th }}$ DLR parabolic flight campaign and 2.) after 5-60 min simulated microgravity provided by a fast rotating $2 \mathrm{D}$ clinostat. Due to the technical limitation of the used DLR clinostat device (experiment stop by activation of a tilting mechanisms pouring the cell suspension into the fixative), ultra-short clinorotation experiments (less than 1 min incubation time) were not possible. Using these microgravity platforms primary human CD4+ T lymphocytes were exposed to altered gravity conditions, either non-stimulated or stimulated with ConA/CD28. Due to the technical limitation (cell numbers and culture volumes) and logistical constraints (experiment preparation, execution and sample recovery), flow cytometry analysis was chosen as the most appropriate method for quantification of a wide range of signal molecules in a small sample size. The number of experimental groups, the group size and the number of different analysis parameters were dictated by the technical conditions and were strictly limited by the maximal cell number.

Results were compared to a MASER-12 sounding rocket experiment that was conducted previously using the same cell type and activation- and fixation regimes [27] allowing to compare our findings between 3 different research platforms and microgravity time periods.

The results that we got for the individual markers partly differ among the experiments from the different microgravity platforms. An example is the reducing effect of altered gravity on CD3 surface abundance after 20 seconds observed during parabolic flight, and the lack of gravi-sensitivity of CD3 during 5 min clinorotation (both non-activated T lymphocytes). The same situation was found for IL-2R. Besides the obvious assumption that different time duration of microgravity can lead to different cellular reactions, it must be kept in mind that such differences are not necessarily solely due to the different time duration, but can also be influenced by the different characteristics of the used microgravity platforms with respect to the quality of the provided gravitational changes. Concerning the simulated microgravity during clinorotation the quality of the "weightlessness", (meaning that the system does not sense any accelerating forces), depends on the rotation speed, the radius of the samples, but also on the systems threshold for sensing acceleration forces [29]. The latter is basically unknown, meaning that is not sure if and to what degree the cells in our system sense the remaining $2 \times 10^{-3} \mathrm{~g}$ acceleration forces in the clinostat. Therefore clinorotation-induced microgravity is called "simulated" microgravity, and this limitation must be kept in mind comparing the results to "real microgravity" platforms. On the other hand, clinorotation has the clear advantage that it does not require a phase of hypergravity prior to microgravity, as it is unavoidable in parabolic flight and sounding rockets experiments. Such hypergravity 
phases can make it difficult to distinguish between hypergravity effects and effects of altered gravity in general, and effects of microgravity might be masked by hypergravity effects that extend into the $\mu \mathrm{g}$ phase. In our experiments, we had to face this restriction for the down regulation of CD3 in hyp-g and in $\mu$ g samples during parabolic flight, which must therefore be understood as sensitivity to altered gravity instead of sensitivity to a gravity below or above $1 \mathrm{~g}$. In the suborbital flight experiment, we also observed a very strong downregulation of CD3 upon the hyp-g phase (Table 1), which might mask an effect of microgravity in the following 6 min phase. Additionally, the hypergravity phase of a sounding rocket flight has other physical characteristics than the hypergravity phase of a parabolic flight.

\section{Initial down-regulation and adaptation of CD3 surface expression in microgravity}

In our study, non-activated $\mathrm{T}$ cells showed a rapid downregulation of CD3 surface expression during the hyp-g phase of the parabolic flight, which was not reconstituted during the following 20 seconds of $\mu \mathrm{g}$ phase. After 5 min clinorotation, the expression of CD3 on the cell surface of non-activated T cells was reduced in both, the $1 \mathrm{~g}$ and the $\mu \mathrm{g}$ samples, thus no simulated microgravity-induced effect could be detected. In contrast, in activated $\mathrm{T}$ lymphocytes a clear difference between the $1 \mathrm{~g}$ and the $\mu \mathrm{g}$ sample was detected, an effect obviously due to the gravitational change. In accordance with this, exposure of CD4+ T lymphocytes to different durations of simulated microgravity also demonstrated a reduced surface expression of CD3 after $5 \mathrm{~min}$ and $15 \mathrm{~min}$ microgravity in comparison to the $1 \mathrm{~g}$ samples in activated T lymphocytes. However, this difference in the CD3 surface expression disappeared within $30 \mathrm{~min}$.. These experiments suggest, that CD3 surface expression is sensitive for altered gravity and adapts to altered gravity with time.

In our preceding study on board of the sounding rocket MASER-12 providing 6 min real microgravity, we found a reduced CD3 surface expression after the hyp-g phase supporting the suggested gravisensitivity. Furthermore, CD3 surface expression reconstituted after $\mathrm{T}$ cell activation during $1 \mathrm{~g}$ conditions but not in microgravity [27]. Investigations of TCR internalization in stimulated human PBMCs using rotating wall vessel system revealed that CD3 internalization was delayed in simulated microgravity [30] an effect in accordance with our findings of gravity-dependence of CD3 surface expression.

ZAP-70 is reduced in activated T cells in simulated microgravity

Upon T lymphocyte activation, ZAP-70 is recruited to the doubly phosphorylated $\zeta$-chain of the TCR at the plasma membrane [35], where it phosphorylates LAT protein, which leads to interleukin production, $\mathrm{T}$ cell proliferation and differentiation [36, 37]. Furthermore, ZAP-70 participates in regulation of cytoskeleton modifications, adhesion and mobility of T-lymphocytes. ZAP-70 is also required for TCR-CD3 complex internalization [38].

ZAP-70 was not influenced during the parabolic flight experiment in non-activated $\mathrm{T}$ cells, which could be confirmed during 5 min clinorotation. However, exposure of activated $\mathrm{T}$ cells to simulated microgravity led to a significant decrease of the ZAP-70 compared to the $1 \mathrm{~g}$ sample. Similarly to these results, it has been reported that more than 2 -fold downregulation of ZAP-70 occurred after 96 hours simulated microgravity using rotating wall vessels [39, 40].

Since ZAP-70 is degraded in parallel with TCR internalization upon T cell activation [41], it can be assumed that degradation is enhanced by microgravity and thus, transduction of TCR mediated signaling leading to formation of the immunological synapse, $\mathrm{T}$ cell polarization, proliferation and differentiation is disturbed.

6 min real microgravity on board of MASER-12 did not reveal any effect of microgravity on ZAP-70. However, the preceding hypergravity phase led to a strong decrease of ZAP-70, thus ZAP-70 degradation might already have occurred during the hyp-g phase, overlaying any microgravity-specific effect [27].

Tyr171-phosphorylated LAT is reduced in hypergravity

In the parabolic flight experiment, the phosphorylation of LAT at Tyr171 in nonactivated $\mathrm{T}$ cells was reduced during the hyp-g phase and was not reconstituted during KARGER 
the following $20 \mathrm{sec} \mu \mathrm{g}$ phase. In contrast phosphorylated LAT in non-activated T cells was not influenced by 5 min simulated microgravity during clinorotation. Phosphorylated LAT in ConA/CD28 activated cells was not statistically shown to be different between $1 \mathrm{~g}$ and $\mathrm{s}-\mu \mathrm{g}$ samples (this might be due to a rather high deviation in the $1 \mathrm{~g}$ samples), but it seems that in $s-\mu$ g samples the level of phosphorylated LAT is higher. Thus, a sensitivity of LAT phosphorylation at Tyr171 was shown in parabolic flight but could not be proven during simulated microgravity.

\section{Reduced IL-2R surface expression after 30 minutes clinorotation}

Non-activated T cells exhibited rapid downregulation of IL-2R surface expression during the hyp-g phase of the parabolic flight, which was not reconstituted during the following 20 sec $\mu$ g phase.

The exposure of non-activated and activated T lymphocytes to 5 minutes simulated microgravity during 2D clinorotation showed no difference between IL-2R surface level of the the $\mu \mathrm{g}$ group and the $1 \mathrm{~g}$ group. This results suggest that IL-2R is sensitive to hypergravity but not to simulated microgravity after $5 \mathrm{~min}$. However, after 30 minutes simulated microgravity, a significantly reduced IL-2R surface expression was observed, which continued over one hour of clinorotation. This effect of microgravity had its onset either quite late compared to the other investigated parameters, or it was just under the detection level and became more pronounced and significant with time. A late onset of an effect of clinorotation would be unique among the here investigated molecules. Nevertheless these findings support the results of previous gene expression studies: Both IL-2 and IL-2R mRNA expression were downregulated in microgravity experiments [26, 42]. Since IL-2 and IL-2 receptor interaction transduces a crucial signal for full $\mathrm{T}$ cell activation and proliferation, we suppose that reduced IL-2R stimulation could contribute to reduced proliferative response of activated T cells in microgravity [7].

\section{Different effects of microgravity on MAPK phosphorylation}

Alterations of gravity during the parabolic flight experiment as well as during clinorotation did not affect phosphorylation and therefore activation of p44/42 MAPK. These results suggest that $\mathrm{p} 44 / 42$ MAPK is not influenced by altered gravity.

However, in the MASER-12 experiment, we found that phosphorylation of p44/42 MAPK was reduced in non-activated T cells after 6 min microgravity, but not in activated T cells. P-p44/42 MAPK was also reduced during the hyp-g phase [27]. In a previous study with Jurkat T cells, we detected an enhanced phosphorylation level of p44/42 MAPK in CD3/ CD28 stimulated as well as non-stimulated Jurkat T cells after 5 minutes clinorotation and an enhanced phosphorylation level of MEK [15]. During a parabolic flight experiment with 20 seconds real microgravity, we detected an enhanced MEK phosphorylation in stimulated, but not in non-stimulated Jurkat cells [15]. The MAPK cascade is a central signal system which is triggered and inhibited by a multitude of intra- and extracellular events and which comprises various negative and positive feedback loops. Thus, the MAPK cascade is known as an oscillating signaling system $[43,44]$ and thus, only kinetic studies with various time points would probably allow to evaluate the effect of gravity on the MAPK signaling cascade.

\section{Acetylation of histone $\mathrm{H} 3$ is regulated by gravity}

Histone $\mathrm{H} 3$ acetylation was increased in non-activated as well as in activated $\mathrm{T}$ lymphocytes after 5 minutes simulated microgravity in the 2D clinostat in comparison to the corresponding $1 \mathrm{~g}$ control. However, we detected no changes after 20 seconds microgravity during the parabolic flight experiment. In a rotary cell culture system, reduced histone $\mathrm{H} 3$ acetylation in T lymphocytes was described after 72 hours and 7 days rotation, associated with a reduced HDAC1 level [14]. During the MASER-12 experiment, acetylation of histone $\mathrm{H} 3$ was reduced strongly during the hypergravity phase of the launch, but did not change during the 6 min microgravity phase [27]. Thus, acetylation of histone H3 is regulated by gravity, possibly downregulatd by hypergravity and upregulated by microgravity.

\section{KARGER}




\section{Conclusion}

T lymphocytes are one of the most important regulatory cells of the human immune system. During space flights and in microgravity analogues, dysregulation of $\mathrm{T}$ cell function has been observed in a multitude of studies $[7,8,13-20,45,46]$. We found a rapid decrease of CD3 and IL-2R surface expression and reduced p-LAT after 20 seconds of altered gravity during parabolic flight, decreased CD3 surface expression, reduced ZAP-70 abundance and increased histone H3-acetylation in activated T lymphocytes after 5 minutes of clinorotation and a transient downregulation of CD3 and stable downregulation of IL-2R during 60 minutes of clinorotation. Thus, we assume that a gravity condition around $1 \mathrm{~g}$ is required for the expression of key surface receptors. During the MASER-12 experiment, many key molecules of $\mathrm{T}$ cell signal transduction were not altered, which is probably the consequence of the preceding hypergravity launch phase, masking the microgravity effects afterwards. Indeed, in the clinostat system, where a hypergravity phase is lacking, downregulation of CD3 and IL-2R could be confirmed.

Taken together in this study we have identified single proteins that react sensitive to altered gravity. This indicates that altered gravity can influence key processes of $\mathrm{T}$ lymphocyte signal transduction including receptor dynamics, phosphorylation and histone modification. Nevertheless, as other components of the signaling cascade did not react to altered gravity conditions, we assume that the signaling process during $\mathrm{T}$ cell activation as a whole is not disturbed severely by altered gravity. Therefore, the question for the system or components that react first to altered gravity and lead to the phenotype of inhibited $\mathrm{T}$ lymphocyte function, remains to be elucidated.

Despite the fact that there is broad knowledge about the consequences of altered gravity on the cellular and molecular level in immune cells, it is still unknown by which mechanism cells sense gravity. Comparing the weight of a single cell with the other physical forces within a cell, it is unlikely that the cell can detect the vector of gravity. Searching for the initial gravity sensor, research has been focusing mainly on the cytoskeleton [47]. A popular model for how cells can sense mechanical forces (and possibly gravitational changes) is the idea that the cell cytoskeleton is built in tensegrity architecture, which provides the cell's stability. According to this model the cytoskeleton is in a state of tension, induced by the actin-myosin network, focal adhesions and cell-cell adhesions [48]. Cytoskeleton-associated proteins which are bound to the actin-network of the cytoskeleton can exist in different folding states dependent on the strain in the actin-network, and these folding states can have different affinities to bind other proteins as a part of signal transduction processes [49]. Therefore, by changing the mechanical forces inside a cell, an alteration of gravity could influence the state of cytoskeleton-associated proteins and thereby influence subsequent signal transduction - a conversion of a mechanical into a chemical signal.

$\mathrm{T}$ cell activation and the cytoskeleton are strongly interdependent. The formation of the immunological synapse leads to tightly coordinated remodeling of the actin and microtubule cytoskeleton in the context of the T-cell polarization process [50]. Subsequently the cytoskeleton supports $\mathrm{T}$ cell activation by maintaining cell-to-cell contact, facilitating $\mathrm{T}$ cell receptor triggering and providing a scaffold for protein clustering, translocation and spatial segregation $[51,52]$. Additionally to this physical support, the cytoskeleton has also impact on the signal transduction of $\mathrm{T}$ cell activation by regulating molecular components of the signaling cascade: It was shown that altered polymerization of tubulin and actin is accompanied by modulation of IL-2 signaling at the receptor level [53]. Activation of p44/42 MAPK has been shown to be inducible by mechanical strain transduced through the cytoskeleton [54]. Interestingly the T cell receptor itself (with CD3 as a component) has not only been described to be functionally influenced by the cytoskeletal environment, but it was also described as a mechanosensor [55]. This relationship between the cytoskeleton (and the mechanical forces it can transduce) and the components of $\mathrm{T}$ cell signaling could support the assumption that $\mathrm{T}$ cell signaling can be influenced by different states of tension within the cytoskeleton. 
Several limiting factors for human health and performance in microgravity have been clearly identified for the musculoskeletal system, the immune system and the cardiovascular system during spaceflight conditions. Considering these constraints, substantial research activities are required in order to provide the basic information for appropriate integrated risk management. In particular, bone loss during long stays in microgravity still remains an unacceptable risk for long-term and interplanetary flights. Recently, there is emerging evidence that the immune and skeletal system are tightly linked by cytokine and chemokine networks and direct cell-cell interactions: It has been demonstrated that the immune system and T cells influence metabolic, structural and functional changes in bones directly $[56,57]$. Therefore, knowing the cellular and molecular mechanisms of how gravity influences $\mathrm{T}$ cells is an invaluable requirement for the provision of therapeutic or preventive targets to keep the bone and immune systems of astronauts fully functional during long-term space missions.

\section{Abbreviations}

CC (cell culture control); ConA (Concanavalin A); ESA (European Space Agency); ESRANGE (European Space and Sounding Rocket Range); GC (ground control); H/W (Hardware); IL-2 (Interleukin-2); IL-2R (Interleukin-2 receptor); LAT (Linker of activation of T cells); MAPK (Mitogen-activated protein kinase); PBMC (Peripheral blood mononuclear cells); RFI (Relative fluorescence intensity); SSC (Swedish Space Corporation); ZAP (Zetachain-associated protein kinase 70).

\section{Acknowledgements}

Terminology was used according to the recommendations by the European consortium "Systematic Evaluation of the ground based (micro-) gravity simulation paradigms available in Europe" (ESA contract 4200022650) [33]. We gratefully acknowledge financial support by German Aerospace Center DLR (grant no. 50WB0912). We also gratefully acknowledge the support of (in alphabetic order) Miriam Christen, Nadine Goelz, André Hilliger, Schirin Ibrahim, Sonja Krammer, Brice Moutett, Marianne Ott and Irina Rau.

\section{Disclosure Statement}

The authors declare that they have no competing interests.

\section{References}

1 National Aeronautics and Space Agency: In Gemini Summary Conference: NASA SP-138. Manned Spacecraft Center, Houston, Texas, Scientific and Technical Information Division, National Aeronautics and Space Administration, 1967.

2 National Aeronautics and Space Agency: Gemini Midprogram Conference, Including Experiment Results: NASA SP-121. Manned Spacecraft Center, Houston, Texas, Scientific and Technical Information Division, National Aeronautics and Space Administration, 1966.

3 Mehta SK, Cohrs RJ, Forghani B, Zerbe G, Gilden DH, Pierson DL: Stress-induced subclinical reactivation of varicella zoster virus in astronauts. J Med Virol 2004;72:174-179.

4 Cohrs RJ, Mehta SK, Schmid DS, Gilden DH, Pierson DL: Asymptomatic reactivation and shed of infectious varicella zoster virus in astronauts. J Med Virol 2008;80:1116-1122.

5 Konstantinova IV, Antropova EN, Legen'kov VI, Zazhireı̌ VD: [Reactivity of lymphoid blood cells in the crew of "Soiuz-6", "Soiuz-7" and "Soiuz-8" spacecraft before and after flight]. Kosm Biol Med 1973;7:35-40.

6 Kimzey SL: Hematology and Immunology Studies; in National Aeronautics and Space Agency (ed): Biomedical results from Skylab. Washington, DC, NASA SP-377, 1977, pp 249-282.

7 Cogoli A, Tschopp A, Fuchs-Bislin P: Cell sensitivity to gravity. Science 1984;225:228-230.

8 Guéguinou N, Huin-Schohn C, Bascove M, Bueb J, Tschirhart E, Legrand-Frossi C, Frippiat J: Could spaceflight-associated immune system weakening preclude the expansion of human presence beyond Earth's orbit? J Leukoc Biol 2009;86:1027-1038. 
9 Cogoli A: Gravitational physiology of human immune cells: a review of in vivo, ex vivo and in vitro studies. J Gravit Physiol 1996;3:1-9.

10 Sonnenfeld G: Space flight, microgravity, stress, and immune responses. Adv Space Res 1999;23:19451953.

11 Cubano LA, Maldonado HM: Immune cells under altered gravity conditions. Bol Asoc Med P R 2006;98:223-228.

12 Schwarzenberg M, Pippia P, Meloni MA, Cossu G, Cogoli-Greuter M, Cogoli A: Signal transduction in T lymphocytes--a comparison of the data from space, the free fall machine and the random positioning machine. Adv Space Res 1999;24:793-800.

13 Thiel CS, Paulsen K, Bradacs G, Lust K, Tauber S, Dumrese C, Hilliger A, Schoppmann K, Biskup J, Gölz N, Sang C, Ziegler U, Grote K, Zipp F, Zhuang F, Engelmann F, Hemmersbach R, Cogoli A, Ullrich O: Rapid alterations of cell cycle control proteins in human T lymphocytes in microgravity. Cell Commun. Signal 2012;10:1.

14 Singh KP, Kumari R, Dumond JW: Simulated microgravity-induced epigenetic changes in human lymphocytes. J Cell Biochem 2010;111:123-129.

15 Paulsen K, Thiel C, Timm J, Schmidt PM, Huber K, Tauber S, Hemmersbach R, Seibt D, Kroll H, Grote K, Zipp F, Schneider-Stock R, Cogoli A, Hilliger A, Engelmann F, Ullrich O: Microgravity-induced alterations in signal transduction in cells of the immune system. Acta Astronautica 2010;67:1116-1125.

16 Mangala LS, Zhang Y, He Z, Emami K, Ramesh GT, Story M, Rohde LH, Wu H: Effects of simulated microgravity on expression profile of microRNA in human lymphoblastoid cells. J Biol Chem 2011;286:32483-32490.

17 Galimberti M, Tolić-Nørrelykke IM, Favillini R, Mercatelli R, Annunziato F, Cosmi L, Liotta F, Santarlasci V, Maggi E, Pavone FS: Hypergravity speeds up the development of T-lymphocyte motility. Eur Biophys J 2006;35:393-400.

18 Uva BM, Masini MA, Sturla M, Tagliafierro G, Strollo F: Microgravity-induced programmed cell death in astrocytes. J Gravit Physiol 2002;9:P275-276.

19 Cogoli A, Cogoli-Greuter M: Activation and proliferation of lymphocytes and other mammalian cells in microgravity. Adv Space Biol Med 1997;6:33-79.

20 Boonyaratanakornkit JB, Cogoli A, Li C, Schopper T, Pippia P, Galleri G, Meloni MA, Hughes-Fulford M: Key gravity-sensitive signaling pathways drive T cell activation. FASEB J 2005;19:2020-2022.

21 Chang TT, Walther I, Li C, Boonyaratanakornkit J, Galleri G, Meloni MA, Pippia P, Cogoli A, Hughes-Fulford M: The Rel/NF- $\mathrm{BB}$ pathway and transcription of immediate early genes in T cell activation are inhibited by microgravity. J Leukoc Biol 2012;92:1133-1145.

-22 Smith-Garvin JE, Koretzky GA, Jordan MS: T cell activation. Annu Rev Immunol. 2009;27:591-619.

23 Zhang W, Sloan-Lancaster J, Kitchen J, Trible RP, Samelson LE: LAT: the ZAP-70 tyrosine kinase substrate that links T cell receptor to cellular activation. Cell 1998;92:83-92.

-24 Bubeck Wardenburg J, Fu C, Jackman JK, Flotow H, Wilkinson SE, Williams DH, Johnson R, Kong G, Chan AC, Findell PR: Phosphorylation of SLP-76 by the ZAP-70 protein-tyrosine kinase is required for T-cell receptor function. J Biol Chem 1996;271:19641-19644.

25 Finco TS, Kadlecek T, Zhang W, Samelson LE, Weiss A: LAT is required for TCR-mediated activation of PLCgamma1 and the Ras pathway. Immunity 1998;9:617-626.

26 Cogoli A: The effect of hypogravity and hypergravity on cells of the immune system. J Leukoc Biol 1993;54:259-268.

27 Tauber S, Hauschild S, Crescio C, Secchi C, Paulsen K, Pantaleo A, Saba A, Buttron I, Thiel CS, Cogoli A, Pippia P, Ullrich O: Signal transduction in primary human T lymphocytes in altered gravity - results of the MASER-12 suborbital space flight mission. Cell Commun. Signal 2013;11:32.

28 Gerathewohl SJ: Zero-G devices and weightlessness simulators: Report for the Armed Forces-NAS-NRC Committee on Bioastronautics Panel on Acceleration, National Academy of Sciences, National Research Council, 1961.

29 Muller HJ: Approximation to a gravity-free situation for the human organism achievable at moderate expense. Science 1958;128:772.

30 Hashemi BB, Penkala JE, Vens C, Huls H, Cubbage M, Sams CF: T cell activation responses are differentially regulated during clinorotation and in spaceflight. FASEB J. 1999;13:2071-2082.

-31 Morrow MA: Clinorotation differentially inhibits T-lymphocyte transcription factor activation. In Vitro Cell. Dev Biol Anim 2006;42:153-158.

-32 Hemmersbach R, von der Wiesche M, Seibt D: Ground-based experimental platforms in gravitational biology and human physiology. Signal Transduction 2006;6:381-387. 
-33 Herranz R, Anken R, Boonstra J, Braun M, Christianen, Peter C M, Geest M de, Hauslage J, Hilbig R, Hill, Richard J A, Lebert M, Medina FJ, Vagt N, Ullrich O, van Loon, Jack J W A, Hemmersbach R: Groundbased facilities for simulation of microgravity: organism-specific recommendations for their use, and recommended terminology. Astrobiology 2013;13:1-17.

-34 Cumming G, Fidler F, Vaux DL: Error bars in experimental biology. J. Cell Biol. 2007;177:7-11.

-35 Chan AC, Iwashima M, Turck CW, Weiss A: ZAP-70: a 70 kd protein-tyrosine kinase that associates with the TCR zeta chain. Cell 1992;71:649-662.

-36 Sommers CL, Samelson LE, Love PE: LAT: a T lymphocyte adapter protein that couples the antigen receptor to downstream signaling pathways. Bioessays 2004;26:61-67.

-37 Zhang W, Trible RP, Zhu M, Liu SK, McGlade CJ, Samelson LE: Association of Grb2, Gads, and phospholipase C-gamma 1 with phosphorylated LAT tyrosine residues. Effect of LAT tyrosine mutations on T cell angigen receptor-mediated signaling. J Biol Chem 2000;275:23355-23361.

38 Wang HY, Altman Y, Fang D, Elly C, Dai Y, Shao Y, Liu YC: Cbl promotes ubiquitination of the T cell receptor zeta through an adaptor function of Zap-70. J Biol Chem 2001;276:26004-26011.

39 Sundaresan A, Pellis NR: Microgravity induced selective lesions in immunosignaling: Upstream targets in lymphocytes. 34th COSPAR Scientific Assembly, The Second World Space Congress 2002; Available from: http://adsabs.harvard.edu/abs/2002 cosp...34E3021S.

40 Pellis NR, Sundaresan A: Microgravity and Cellular Consequences in Lymphocyte Function. Bio Science 2004;Available from: http://naca.larc.nasa.gov/search.jsp?R=20050217302\&qs $=\mathrm{N}=4294950110+4294817689+4294360333$.

41 Penna D, Müller S, Martinon F, Demotz S, Iwashima M, Valitutti S: Degradation of ZAP-70 following antigenic stimulation in human T lymphocytes: role of calpain proteolytic pathway. J Immunol 1999;163:50-56.

42 Walther I, Pippia P, Meloni MA, Turrini F, Mannu F, Cogoli A: Simulated microgravity inhibits the genetic expression of interleukin-2 and its receptor in mitogen-activated T lymphocytes. FEBS Lett 1998;436:115118.

43 Kholodenko BN: Negative feedback and ultrasensitivity can bring about oscillations in the mitogenactivated protein kinase cascades. Eur J Biochem 2000;267:1583-1588.

44 Sarma U, Ghosh I: Oscillations in MAPK cascade triggered by two distinct designs of coupled positive and negative feedback loops. BMC Res Notes 2012;5:287.

45 Schmitt DA, Hatton JP, Emond C, Chaput D, Paris H, Levade T, Cazenave JP, Schaffar L: The distribution of protein kinase $C$ in human leukocytes is altered in microgravity. FASEB J 1996;10:1627-1634.

46 Cogoli A, Bechler B, Cogoli-Greuter M, Criswell SB, Joller H, Joller P, Hunzinger E, Müller O: Mitogenic signal transduction in T lymphocytes in microgravity. J Leukoc Biol 1993;53:569-575.

47 Vorselen D, Roos WH, MacKintosh FC, Wuite, Gijs J L, van Loon, Jack J W A: The role of the cytoskeleton in sensing changes in gravity by nonspecialized cells. FASEB J 2014;28:536-47.

48 Ingber DE: Integrins, tensegrity, and mechanotransduction. Gravit Space Biol Bull 1997;10:49-55.

49 Vogel V, Sheetz M: Local force and geometry sensing regulate cell functions. Nat Rev Mol Cell Biol 2006; 7:265-275.

50 Soares H, Lasserre R, Alcover A: Orchestrating cytoskeleton and intracellular vesicle traffic to build functional immunological synapses. Immunol Rev 2013;256:118-132.

51 Gomez TS, Billadeau DD: T cell activation and the cytoskeleton: you can't have one without the other. Advances Immunol 2008;97:1-64.

52 Beemiller P, Krummel MF: Mediation of T-cell activation by actin meshworks. Cold Spring Harb Perspect Biol 2010;2:a002444.

53 Goebel J, Forrest K, Wills-Karp M, Roszman TL: Tubulin polymerization modulates interleukin-2 receptor signal transduction in human T cells. J Recept Signal Transduct Res 2006;26:87-106.

54 Jessop HL, Rawlinson, S C F, Pitsillides AA, Lanyon LE: Mechanical strain and fluid movement both activate extracellular regulated kinase (ERK) in osteoblast-like cells but via different signaling pathways. Bone 2002;31:186-194.

55 Kim ST, Takeuchi K, Sun ZJ, Touma M, Castro CE, Fahmy A, Lang MJ, Wagner G, Reinherz EL: The alphabeta T cell receptor is an anisotropic mechanosensor. J Biol Chem 2009;284:31028-31037.

56 Takayanagi H, Ogasawara K, Hida S, Chiba T, Murata S, Sato K, Takaoka A, Yokochi T, Oda H, Tanaka K, Nakamura K, Taniguchi T: T-cell-mediated regulation of osteoclastogenesis by signalling cross-talk between RANKL and IFN-gamma. Nature 2000;408:600-605.

57 Takayanagi H: Osteoimmunology: shared mechanisms and crosstalk between the immune and bone systems. Nat Rev Immunol 2007;7:292-304. 